\title{
THE BETTER USE OF THE WORLD'S FAUNA FOR FOOD
}

$\mathrm{T}$ HAT a large proportion of the world's population, especially in the technologically under-developed countries, suffers from either chronic or seasonal under-nutrition is well known. In many of these countries there is a continuous shortage of dietary calories, the ultimate effect of which is to slow down most human activities, with the apparent exception of the rate of reproduction. Not less serious than calorie shortage in its effect on the younger gioups of the population and on pregnant and lactating women is the acute deficiency of dietary protein, which may occur with or without a calorie shortage, and is most obvious in its effects on the post-weaning child up to the age of about five years. Such protein deficiency is particularly marked in animal protein, usually richer in the amino-acids essential for growth and usually accompanied by a more valuable assortment of mineral salts, trace elements and vitamins than is vegetable protein.

The Freedom from Hunger Campaign of the Food and Agriculture Organization has as its objectives the improvement in quality as well as in quantity of food consumed in the existing hungry countries. It was therefore a most timely effort of the Institute of Biology to arrange a symposium, held during October 27-28 in the Royal Geographical Society's rooms, on "The Better Use of the World's Fauna for Food".

In the opening session, under Sir Julian Huxley's chairmanship, Dr. Francis Aylward (Borough Polytechnic, London), who has fairly recently returned from an extensive nutritional mission for the Food and Agriculture Organization in one of the underdeveloped countries, discussed the methods of assessment: (1) of protein requirements of individuals and communities ; (2) of protein supplies actually available in a country; (3) of protein deficits on a regional, national and world-wide basis. The available statistical evidence of protein deficits, though not always as accurate as one could wish, was sufficiently convineing, apart from the additional evidence afforded by direct observations, by morbidity records and by mortality statistics. Though it was highly desirable to remove some of the uncertainty regarding the quality of the statisties and for further research on physiological requirements to be carried out, the need was even more urgent to use the scientific and. technical knowledge now available in an intensive effort to improve indigenous protein supplies by the adoption of a more vigorous agricultural policy (in the widest sense, to include animal husbandry, fisheries and controlled utilization of wild fauna) and also by more thorough application of modern food science to conservation and distribution of food.

"The Relative Merits of Plant and Animal Proteins" was the title of the paper given by Dr. A. E. Bender, whose important work on the assessment of the nutritional value of proteins and mixtures of proteins is well known to British nutritionists. Dr. Bender's contribution provided a useful epitome of the methods by which an assessment may be made of the comparative dietary values of different individual proteins, or mixtures of proteins. He related the figures obtained to needs at different ages and in different physiological conditions. The proteins of cassava, plantain, breadfruit and sweet potatoes are inadequate for health of child or adult; those of rice, yams, millet and wheat can maintain the adult, but not the adolescent or the child. Some seed proteins, especially those of legume seeds (and particularly if two or more 'oil-seed' proteins, freed from oil, are mixed), will provide an adequate protein supply for all ages, if they constitute a sufficient proportion of the diet. The advantages and disadvantages of plant and animal proteins were compared, plant proteins being usually the cheaper, with a bigger yield per acre than animal proteins; recent attempts have been made to produce a cheap high-protein food mainly or even exclusively from vegetable sources (for example, 'Incaparina' in Central America). A mixture of animal with a poorer vegetable protein often gave a protein utilization result for the mixture almost as high as if the whole had been animal protein.

Religious prejudices in certain countries-not always under-developed countries-and local taboos more frequently handicapped the consumption of animal than of vegetable protein-rich foods, but the former were, for most people, tastier and more acceptable.

Though the answer to the protein-shortage problem in some countries might be intelligent vegetarianism, yet the advantages for the agricultural productivity of land of mixed farming, and the importance especially to the vulnerable groups of the population of having in the diet a reasonable percentage of protein food from animal sources, could not be overlooked.

Mr. T. J. Lansbury, in discussing potentialities of animal and particularly ruminant husbandry in West Africa, described the existing handicaps of absence of enclosure and of any intelligible system of land tenure, of 'night kraaling' with its consequent decrease in live-weight gain, of disease and particularly of the present of tsetse fly in many of the wooded areas, of unfertilized, mineral-poor pasture and semi-starvation of stock during long periods of drought, of catastrophic overstocking where cattle and even sheop and goats were regarded more as status symbols than as sources of food, being associated with bride price, ceremonial gifts and ritual sacrifice at traditional ceremonies.

The local cattle were nevertheless capable of good growth and production if adequate and controlled water supplies and the provision of dry-season supplementary foods could be organized. Two indigenous breeds of eattle, the n'dama and the West African dwarf shorthorn had considerable resistance to trypanosomiasis and were being introduced with advantage into certain tsetse-infested areas where welldistributed rainfall gave good grass production. The substitution of nomadic husbandry by mixed farming, enabling pastures to be suitably fertilized and fodder to be conserved for the dry season, entailed formidable sociological problems as well as wide dissemination of improved techniques.

Mr. Lansbury considered that pig and poultry husbandry probably offered fewer difficulties than cattle husbandry and that it should be possible to use modern knowledge to expand the pig and poultry industry rapidly and efficiently in West Africa, with great benefit to human nutrition.

The text of a paper by Prof. A. G. Bannikov, of the Academy of Veterinary Sciences, Moscow, on the 
exploitation of the saiga antelope in the U.S.S.R. had been circulated, but unfortunately had to be discussed in the author's unexpected absence.

This antelope, which now occurs in increasing numbers in both European and Asiatic U.S.S.R. territories, was in the 1920's, as the result of uncontrolled, destructive hunting, almost extinct. Protective laws, introduced in 1919, intended merely to preserve the remnants of the species as a rare curiosity, had little effect at first, but in the 1930's and 1940's a rapid increase in numbers became evident and to-day the total saiga population in Europe is about 500,000 , and in Asiatic U.S.S.R. about 1,500,000, mainly in the steppe plains and semi-deserts. It is a fertile ruminant, congregates in large and mobile herds and is now being systematically and rationally hunted, usually at night by organized groups of marksmen equipped with motor-vehicles with powerful headlights which attract the antelopes. Prof. Bannikov stated that the recovery of the saiga from near extinction to profitability is a vindication of the principles of intelligent nature conservation.

The use of an entirely different genus of animal for food was recorded by Dr. R. Orraca-Tetteh, who described the habits, collection and utilization in the diet of the giant African snail, Achatina.

Achatina, the largest living land mollusc, with, it was stated, a foot which when fully expanded might reach $30 \mathrm{~cm}$. in length, is found in different parts of Africa, south of the Sahara. During the rainy season the snail population in the forests is often large. The animals are particularly active at night, browsing on tender leaves and fallen fruit, and growing rapidly. They are collected usually before sunrise and sent quickly to the market. They are killed by dropping snail and shell into hot water; the molluscs are then removed by hand. They may be eaten at once in soup or stew, or preserved for three months or more by smoking. The fresh samples contain about 16 per cent of protein, with a small amount of fat, some thiamine, riboflavin and niacin, and more than 70 per cent of moisture; the protein has a high content of lysine.

In parts of West Africa the snail is a very popular article of diet, and can be purchased cheaply during the rainy season.

Dr. L. Harrison Matthews discussed the problems and potentialities of wild-game ranching, which appears to be increasing, in Africa. The existing species of wild vegetivorous fauna in large areas in Africa have been established there long enough to become adjusted to their environment, making use of all the food resources, some by grazing, others browsing, others by eating the upper leaves of trees. The bio-mass of this wild fauna which is commercially exploitable is large, especially if natural predators are kept in check.

Most cattle ranchers coming into these areas in the past have destroyed or driven away the wild ungulates, regarding them as pests, though the cattle brought in have made less-efficient use of the vegetable food available.

The deliberate ranching of mixed wild fauna if they can be profitebly cropped for human food is a commercial possibility that is now being exploited with some success. In Southern Rhodesia it is said to be more profitable than cattle ranching, while in the Republic of South Africa between 2,000 and 3,000 farmers are said to be stocking game, including such animals as zebra, wildebeest, impala, eland, kudu. The resistance of these animals to disease is greater than that of imported cattle. Transport and marketing problems in the sale of meat and hides are being solved. It was thought that once game ranching becomes commercially established, the extinction of the wild fauna concerned will be unlikely.

Efficient food processing preserves the nutritive value of the raw materials and yields a product acceptable to the consumer. P. L. Pellet and D. S. Millar, of the London School of Hygiene and Tropical Medicine, considered the processing and preservation of meat in under-developed areas from both these points of view. In tropical environments the slaughter of stock and the production of dressed carcasses either for immediate consumption or for preservation are fraught with temperature, and other, hazzrds. Further, the particular, and to Western eyes rather peculiar, food preferences of the local consumers have to be taken into account; for example, "To the Ghanian, the eating of, or rather the chewing of, meat is a pleasure to be taken leisurely, and consequently he regards tender flesh as low in value". Methods of preservation can seriously lower the nutritive value of any kind of meat or fish, but traditional preserved meats such as biltong, charqui, pemmican and kavurma are highly acceptable to the local consumers, and often showed little protein damage. If traditional methods of preservation were studied scientifically, many could be extended with advantage to meet the immediate protein needs of populations of under-developed countries. More sophisticated, modern methods such as refrigeration, canning, dehydration, vacuum contact drying, vacuum oil dehydration, production of meat powders, with the modern equipment necessary could be brought in as capital resources increased and indigenous food preferences and habits permitted.

The waters of the Earth (seas, lakes and rivers) occupy 75 per cent of its surface, but account for only 10 per cent of the world's food supply. The second day of the symposium was devoted to the problem of increasing food supplies from these sources. Mr. E. B. Parrish (Department of Agriculture and Fisheries for Scotland, Aberdeen) introduced the complex question of how to obtain maximum yield from traditional methods of fishing. The increasing intensity of fishing in certain areas such as the North Sea and north-west Atlantic has led to a decrease in the size and age of the fish caught and to a diminution in profitability of fishing. To prevent 'overfishing' of these areas, international conventions have been arrived at "for the investigation, protection and conservation of the fisheries" in order to make possible the maintenance of a "maximum sustained catch". Regulations for the fixing of catch quotas, for closed seasons, for closed fishing areas, for controlling the size at which fish could be caught by the fishing gear. for fixing of minimum landing-size limits, have been tried with mixed success.

In the conservation and management of fisheries large demands are made on scientific methods of investigating the population dynamics of the exploited fish stocks; these demands continue after regulations have been put into practice, to assess the responses of the exploited stock to them and give more precise adjustments of present fishing intensity to the maintenance of adequate future fish supplies.

Mr. F. D. Ommanney gave a fascinating account of sea fisheries in tropical areas. The poor gear and low status of the average tropical fisherman are slowly improving and in British dependent territories the work of fishery officers has led to major advances, 
largely a result of fitting fishing boats with enginesoutboard for the smaller and inboard for the larger craft, and partly by improved nets. At the same time, attempts have been and are being made, as a result of increased landings of fish, to reduce the price to the consumer.

Some Governments in British dependent territories, or those formerly dependent, have provided special fishing vessels for exploratory and pioneering work. Stations for fisheries investigations have been established in a few tropical countries, but owing to the vagaries of Government support have not been entirely successful. For the progress of tropical fisheries and the optimal use, in protein-hungry, maritime countries, of sea fauna for food, active and adequately supported research stations are urgently needed.

Improvements and trends of development in marine fishing methods and gear were the subject of a technical, well-illustrated contribution from Dr. J. Schärfe, of the Food and Agriculture Organization (Rome). Fish location and detection have been aided by aerial scouting and still more by fish-finding echo sounders and rangers. These need much skill and practical experience to use to full advantage. This technique is now firmly established for all medium and large fishing vessels in the developed countries. Synthetic fibres stronger and more elastic than natural fibres are being used very widely for nets and lines, and have inspired new ideas in the design and operation of fishing gear and methods.

Larger stern-trawlers of up to 3,000 h.p. with freezers, cold storage and in some cases manufacturing plant for oil and fish meal can now go quickly to distant grounds and remain away from home ports for extended periods. Fishing fleets exist with boats specialized for searching, eatching, factory work, transport, hospital and recreation facilities. Midwater trawling with echo sounding is a modern line of development which is likely to have far-reaching results.

Electrical killing or stunning of fish in confined waters has been experimented with with some success and may have a future even for sea fish.

Mr. K. F. Vaas, of Yerseke (Netherlands), pointed out that fish culture in freshwater and brackish ponde was both an ancient and a very widespread craft. Tilapia was cultivated in ponds in Egypt before 2,000 B.C., and a text-book on fish culture was written in China in 475 B.C. Large yields of fish per acre of water surface are obtainable under favourable conditions - the Grand Lac in Cambodia with an area at high water of $10,000 \mathrm{~km}^{2}$ is said to produce $100 \mathrm{kgm}$. fish per hectare.

Tropical ponds give better yields than those of colder climates, but much depends on 'management' in the shape of fertilizers or the introduction of fish foods of various kinds. Fish culture nay be combined with animal husbandry, the dung fertilizing the growth in the ponds of fish food such as diatoms, plants and crustaceans. Production of fish from inland waters has been calculated to be some 18 per cent of the total world catch.

The culture of marine molluses and crustaceans was reported on by $P$. R. Walne, of the Ministry of Agriculture, Food and Fisheries, Fisheries Experiment Station, Conway. In the United Kingdom, shellfish form only $2 \cdot 5$ per cent, in Japan 19 per cent, in the Netherlands 28 per cent, and, rather surprisingly, in the United States 30 per cent of the total fish landings. Oysters and mussels are slow growing, the mussel requiring four years, and the oyster five, to reach marketable size. The meat of the adult oyster or mussel contains some 80 per cent of water and 9-13 per cent of protein, that is, roughly 50 per cent or more of protein on the dry weight. Oysters are probably the most carefully cultivated crop obtainable from the sea. In recent years mechanical methods, including special dredges, are being used for removal of the bivalves to new grounds from time to time, and for final harvesting. Such dredges attached to power-driven boats can work economically on quite low population densities. By this means both the mussel and the oyster stock in Holland is moved several times to assist growth and reduce starfish depredation.

Mr. Walne considered that an important future step in oyster husbandry should be what has been done with practically all agricultural plants and animals, namely, to increase the rate of growth and quality of the stock by breeding and selection.

Some recent advances in the processing of fish were described by Dr. D. L. Nichol, of the Department of Scientific and Industrial Research, Humber Laboratory, Hull, in relation to the more efficient use of this source of food.

'White' fish gutted, washed and stored in ice at sea become stale after 12-15 days, and if distant water voyages are to last longer than the average of 18-20 days (4 days each way to the fishing grounds) apparatus is needed for deep freezing at sea at least part of the catch. In trials carried out in 1956, this method of preservation of whole fish has been proved success. ful and more trawlers are being fitted out with the necessary deep-freeze equipment.

Deop-frozen fish is now being distributed in various forms to consumers. It is necessary to keep the temperature down all elong the distribution chain, and this is not always realized, as the difference between a block of frozen fish at $-20^{\circ} \mathrm{F}$. (a tempera ture at which no deterioration occurs in eight months) and $+20^{\circ} \mathrm{F}$. (a temperature at which deterioration occurs within a month) is not obvious to the operator.

Herring processing presents different problems from that of white fish, as herring fishing is sessonal and the disposal of gluts may arise. Gluts of herrings are usually transformed into oil and fish meal, the latter being utilized in the manufacture of animal feeding stuffs and increasingly in tinned food for domestic pets.

White fish meal prepared from surplus or condemned fish and from fish offal is manufactured in the United Kingdom and abroad in substantial quantities for use in animal feeding stuffs. Fish flour, a deodorized and almost flavourless powder usually made from whole fish, is proving acceptable as an addition to human diet in certain proteindeficient regions.

A paper on the possible farming of the sea from Sir Alister Hardy concluded the symposium. He discussed the possibility of improving the production of plankton and hence of the fish that ultimately depend on plankton for food either by fertilization of limited or confined areas of sea with phosphates and nitrogen or by causing up-welling of the deeper layers of sea-water which are richer in nutritive salts than the upper layers. He also mentioned methods for diminishing the enormous loss of fish that occurs in early life and the possible transporting of young fish from crowded to less-crowded areas.

Recent research has shown that invertebrate competitors of fish on the sea bed, such as starfish, are much more important in limiting the potential supply 
of food available to fish than was formerly realized, and that at least in limited areas such pests might be greatly reduced in numbers by specialized trawling.

To summarize, the following are among the main considerations that emerged from the symposium:

(1) The rapid rise in world population makes it doubly important that there should be increased production and much better utilization for human food of land fauna, both domestic and wild, and of sea fauna.

(2) The potentialities of such increased production are large if present agricultural, animal husbandry and fisheries knowledge is effectively applied, and if the utilization of wild animals is conducted intelligently and under adequate control; these potentialities are immense if sufficient research effort is directed towards the further acquisition of knowledge in these fields, particularly in that of marine biology.

(3) The rate of progress in improving the protein status of malnourished populations will depend largely on indigenous decisions to correlate their farming and their fisheries policy with indigenous nutritional neods, and actively and continuously to stimulate the intelligent knowledgeable local production of fish, flesh and fowl.

The proceedings of the symposium will be published by the Institute of Biology (41 Queen's Gate, London, S.W.7).
H. D. KAY

\section{FIFTH INTERNATIONAL CONGRESS OF BIOCHEMISTRY}

$\mathrm{T}$ HE fifth International Congress of Biochemistry, organized by the U.S.S.R. Biochemical Society and sponsored by the International Union of Biochemistry and the Academy of Science of the U.S.S.R., was held in Moscow during August 10-16, under the presidency of Academician A. I. Oparin. The scientific sessions were held in the imposing building of the University of Moscow which stands on the Lenin Hills and overlooks the historic city. The number of registered participants, about 4,500 together with an additional 1,000 or so guests of the Organizing Committee, was larger than any previous congress, and it seems that each congress, from the first, which was held in Cambridge in 1949, to the present one in Moscow, attracts more and more workers who are interested in one or many aspects of the broad subject of biochemistry.

The congress held its opening ceremony in the impressive Palace of Sports of the Central Lenin Stadium and the session closed with a masterly lecture on "The Structure and Function of Subcellular Particles", by Prof. D. E. Green (United States). Unfortunately, poor projection facilities reduced the enjoyment of many participants who were not fortunate enough to be seated near the front of the huge lecture hall. The plenary session was followed by a most enjoyable concert given by the Moscow Symphony Orchestra.

The scientific programme which followed included a series of symposia, and between two and three thousand original contributions given under the auspices of twenty-eight sections. The main congress symposia were held in the large assembly hall of the University or in auditoria of ample seating capacity and were well attended throughout. The symposia covered the following subjects: (1) Biological Structure and Function at the Molecular Level (president, M. F. Perutz, Great Britain); (2) Functional Biochemistry of Cell Structures (O. Lindberg, Sweden); (3) Evolutionary Biochemistry (S. Ochoo, United States); (4) Molecular Basis of Enzyme Action and Inhibition (P. Desnuelle, France); (5) Intracellular Respiration: Phosphorylating and Non-Phosphorylating Reactions (E. C. Slater, Holland); (6) Mechanism of Photosynthesis (H. Tamiya, Japan); (7) Biosynthesis of Lipids (G. Popják, Great Britain); (8) Biochemical Principles of Food Industry (E. Pyanowski, Poland). The main sperkers in these sessions were allowed up to forty minutes to develop their subject and the subsequent speakers fifteen minutes, a half to three-quarters of an hour being set aside at the end of the session for discussion. The time proved to be adequate, and the discussions were usually lively. The arrangements for simultaneous translations in these meet ings were excellent.

Among the many important communications given in the symposia Dr. Britton Chance's demonstration of a new effect in the field of intracellular respiration predicted on theoretical grounds some years ago by Sir Hans Krebs, namely, the reversal of the direction of electron transfer in isolated mitochondria occurring on the addition of adenosine triphosphate and leading to a reduction of pyridine nucleotide was particularly noteworthy; as were Prof. A. L. Lehninger's report on a preparation of hitherto unrecognized components of the chain of oxidative phosphorylation and their relation to the swelling and contraction of mitochondria, and Prof. Lynen's account of the advances he and his colleagues had recently made in the understanding of the role of $(+)$-biotin as a coenzyme of carbon dioxide fixation and transcarboxylation. Prof. E. P. Kennedy (United States) gave an outstanding lecture on lipid biosynthesis. There were, of course, many other new and interesting aspects of fundamental problems presented at the congress, but the author, in common with other participants, was able to hear only a small part of them. Pre-prints of the main congress lectures and of the contributions to the symposia were available to participants before the meeting.

Probably the largest part of the scientific programme was associated with the activities of the twenty-eight sections which held their meetings and discussions in nearly as many rooms scattered throughout the very large University building and in the Departments of Physics and of Chemistry situated a fow minutes walk from the main building. Two of the Sections, those concerned with Immunochemistry and the Biochemistry of Malignant Tumours, held their meetings in the Sternberg Institute of Astronomy, which was unfortunately about a 15-min. walk away from the site of the main congress activities.

Each section had its own interpreter, and language difficulties were thereby reduced to a minimum. Abstracts of the short communications were available in the form of a separate book, and where the text 